\title{
Flow Stress and Hot Deformation Activation Energy of 6082 Aluminium Alloy Influenced by Initial Structural State
}

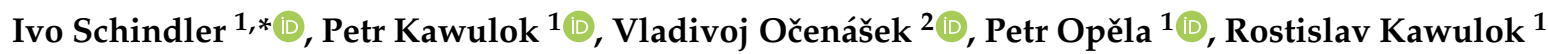 \\ and Stanislav Rusz ${ }^{1}$ \\ 1 Faculty of Materials Science and Technology, VŠB - Technical University of Ostrava, 17. listopadu 2172/15, \\ 70800 Ostrava, Czech Republic; petr.kawulok@vsb.cz (P.K.); petr.opela@vsb.cz (P.O.); \\ rostislav.kawulok@vsb.cz (R.K.); stanislav.rusz2@vsb.cz (S.R.) \\ 2 SVÚM a.s., Tovární 2053, 25088 Čelákovice, Czech Republic; ocenasek@svum.cz \\ * Correspondence: ivo.schindler@vsb.cz; Tel.: +420-596995215
}

Received: 11 October 2019; Accepted: 20 November 2019; Published: 22 November 2019

\begin{abstract}
Stress-strain curves of the EN AW 6082 aluminium alloy with 1.2 Si-0.51 Mg-0.75 Mn (wt.\%) were determined by the uniaxial compression tests at temperatures of $450-550{ }^{\circ} \mathrm{C}$ with a strain rate of $0.5-10 \mathrm{~s}^{-1}$. The initial structure state corresponded to three processing types: as-cast structure non-homogenized or homogenized at $500{ }^{\circ} \mathrm{C}$, and the structure after homogenization and hot extrusion. Significantly higher flow stress appeared as a result of low temperature forming of the non-homogenized material. Hot deformation activation energy $Q$-values varied between 99 and $122 \mathrm{~kJ} \cdot \mathrm{mol}^{-1}$ for both homogenized materials and from 200 to $216 \mathrm{~kJ} \cdot \mathrm{mol}^{-1}$ for the as-cast state, while the $Q$-values calculated from the measured steady-state stress were always higher than those calculated from the peak stress values. For the extruded state of the 6082 alloy, the physically-based model was developed to reliably predict the flow stress influenced by dynamic softening, temperature, strain rate, and true strain up to 0.6 .
\end{abstract}

Keywords: aluminium alloy; microstructure; hot deformation; activation energy; flow stress model

\section{Introduction}

In addition to their chemical composition, the hot forming processes of aluminium alloys are significantly influenced by the initial structure. The state of the structure affects the plastic deformation that can be achieved, and, thus, affects the economic parameters of the production.

The work aimed to determine the influence of the initial structure on selected aspects of hot deformation behaviour of the EN AW 6082 aluminium alloy (AlSi1MgMn). Due to the fine-grained microstructure, this alloy exhibits good resistance to dynamic loading conditions. Its typical applications are as follows: offshore constructions, automotive suspension components, rail coach parts, and mobile cranes components. The age-hardened 6082 alloy offers an excellent combination of mechanical properties and corrosion resistance [1].

Many authors have discussed the influence of homogenization annealing on the course of hot forming processes and final properties of products made of 6082 alloy. The subject of interest is both the intrinsic effect of homogenization on the structure and formation of intermetallic phases [2,3], as well as on the hot forming process [4-6], or on the recrystallization and hardening during heat treatment [7-9]. The paper [10] details the transition from extruded rods to the as-cast and homogenized structure in the production of die forgings. The fine-grained as-cast structure does not change significantly during forging. This structure avoids the formation of surface recrystallized layers that are typical 
of die-forged extruded rods. Since these layers decrease the mechanical properties and the forging surface quality, the initial as-cast structure for die forming is promising at this point.

The homogenizing annealing of the as-cast structure of aluminium alloys before hot forming is currently an essential part of the extrusion technology of rods, which are mainly used for die forging. Its favourable effect on the flow stress is the reason why homogenization annealing of continuously cast material is used in an effort to produce forgings for demanding use in the automotive industry, i.e., rods (horizontal direct chill casting [11]) or strips (twin-belt casting [12]). Omitting homogenization annealing from the die forging process is not planned for this reason, despite the indisputable energy savings. Therefore, information on tests or production of die forgings from non-homogenized as-cast materials is currently not available.

The state of the initial structure before hot forming (extruded, as-cast homogenized, as-cast non-homogenized) significantly affects not only the actual hot forming process but is also reflected in the area of heat treatment. The resulting mechanical, durability, and corrosion properties of the forgings are the result of interaction of the initial structure, the hot deformation parameters, solution annealing, and artificial aging. Therefore, these relatively complicated connections have been the subject of several research works (see References [13-16]).

\section{Characteristics of the Experimental Material}

Three variants of the structural state of the 6082 alloy were investigated (see Table 1 for chemical composition).

Table 1. Chemical composition of experimental material in wt. \%.

\begin{tabular}{|c|c|c|c|c|c|c|c|c|c|}
\hline Alloy & Si & $\mathrm{Fe}$ & $\mathrm{Cu}$ & Mn & $\mathrm{Mg}$ & $\mathrm{Cr}$ & $\mathrm{Zn}$ & $\mathrm{Ti}$ & Al \\
\hline EN AW 6082 & $0.7-1.3$ & $\begin{array}{c}\max . \\
0.50\end{array}$ & $\begin{array}{c}\max . \\
0.10\end{array}$ & $0.4-1.0$ & $0.6-1.2$ & $\begin{array}{c}\max . \\
0.25\end{array}$ & $\begin{array}{c}\max . \\
0.20\end{array}$ & $\begin{array}{c}\max . \\
0.10\end{array}$ & remainder \\
\hline Extruded rod & 0.93 & 0.16 & 0.06 & 0.68 & 0.76 & 0.14 & 0.01 & 0.05 & remainder \\
\hline As-cast rod & 0.93 & 0.15 & 0.07 & 0.53 & 0.74 & 0.13 & 0.01 & 0.03 & remainder \\
\hline
\end{tabular}

They were continuously cast rods with a diameter of $55 \mathrm{~mm}$ in homogenized and non-homogenized states as well as the extruded rod of the same diameter. The homogenizing annealing of the cast rod was carried out at $530^{\circ} \mathrm{C}$ for $8 \mathrm{~h}$ followed by slow air cooling. Homogenization was also carried out before extrusion. The cuttings from three different rods were utilized to produce samples for subsequent hot compression testing. The cuttings were sectioned parallel to the axis along the centreline and metallographically prepared. Metallographic cuts were etched with the Keller's reagent for $30 \mathrm{~s}$ and observed on the inverted light microscope ZEISS Axio Observer Z1m (ZEISS, Jena, Germany). The structure of the cast non-homogenized rod is shown in Figure 1, and the structure after homogenization is shown in Figure 2. The effect of homogenization is apparent on the shape and size of the intermetallic phases deposited at the boundaries of the as-cast grains. Homogenization annealing partially dissolves these particles and rounds them.

The structure of the extruded rod (see Figure 3) is fibrous in the direction of performed extrusion with apparent sub-grains in the softened aluminium matrix. 


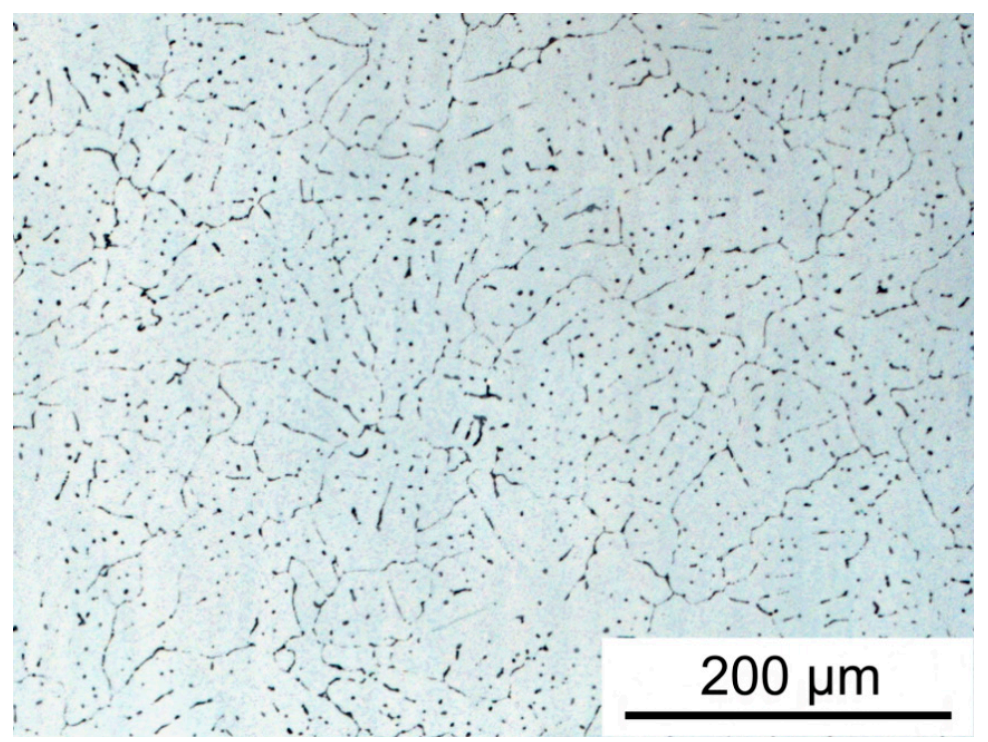

Figure 1. Structure of as-cast grains and intermetallic phase cast rod, which is non-homogenized.

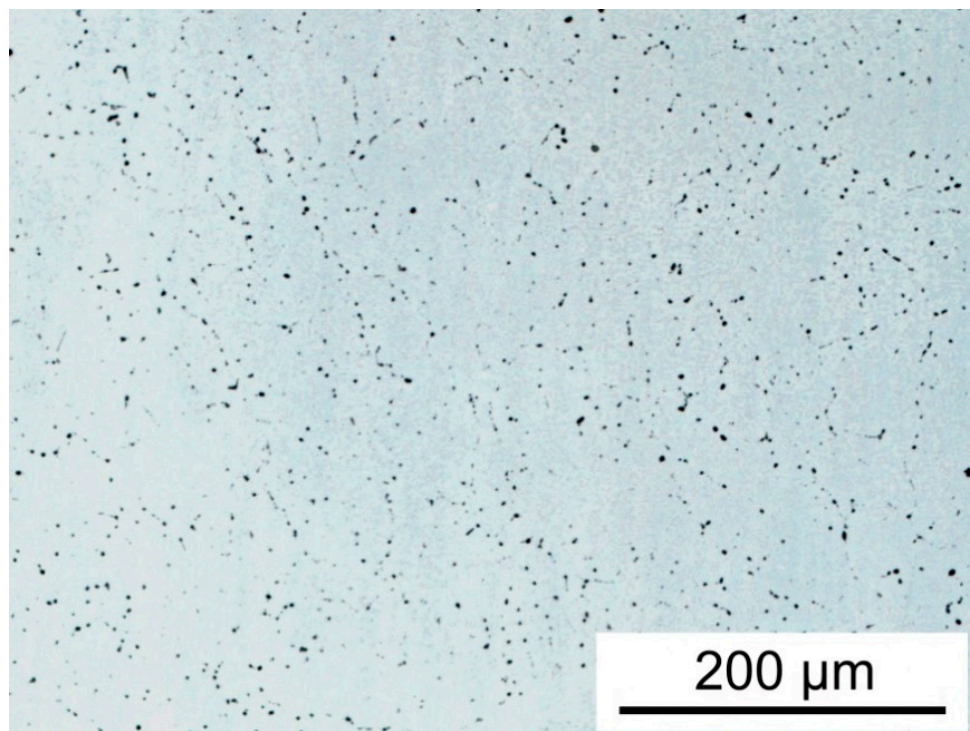

Figure 2. Structure of as-cast grains and intermetallic phase-cast rod, homogenized.

The as-cast structure is formed by the $\alpha$-Al solid solution with the intermetallic phases at grain boundaries. The different nature of the intermetallic phases in the as-cast and extruded structures is apparent from Figures 4-6 obtained by the SEM method (secondary electron imaging). Scanning electron microscope ZEISS EVO 10 (ZEISS, Jena, Germany) with backscatter detector and the Element EDS system was used. In accordance with results published in Reference [8], the intermetallic phases $\beta$-AlFeSi and $\alpha$-AlFeMnSi can be assumed as well as some coarse $\beta-\mathrm{Mg}_{2} \mathrm{Si}$ particles. The change in phase morphology due to homogenization annealing with slow cooling is very evident from a comparison of Figures 1 and 2, respectively (Figures 4 and 5). Homogenization leads to the transformation of the $\beta$-AlFeSi phase into the smaller rounded dispersoids of the $\alpha$-AlFeMnSi type. The fine precipitates should be the particles of the $\beta-\mathrm{Mg}_{2} \mathrm{Si}$ phase, formed by precipitation from the dissolved particles during slow cooling after homogenization $[17,18]$. Plastic deformation causes the intermetallic phases to be crushed into lines parallel to the direction of extrusion that was performed (see Figure 6). This creates a fibrous structure and the size of the larger particles can decrease. The $\alpha$-particle size is more than $10 \mu \mathrm{m}$ in the cast state. After homogenization, it drops to an average size of about $2 \mu \mathrm{m}$. 


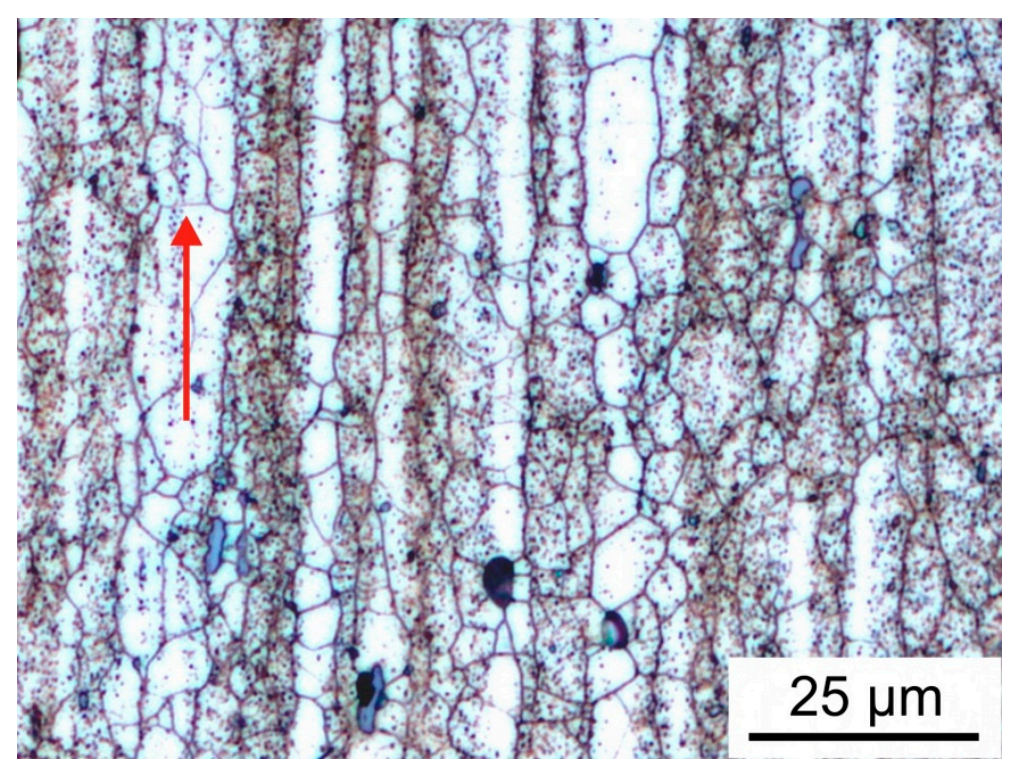

Figure 3. Structure of grains in longitudinal direction-extruded rod (extrusion direction indicated by the red arrow).

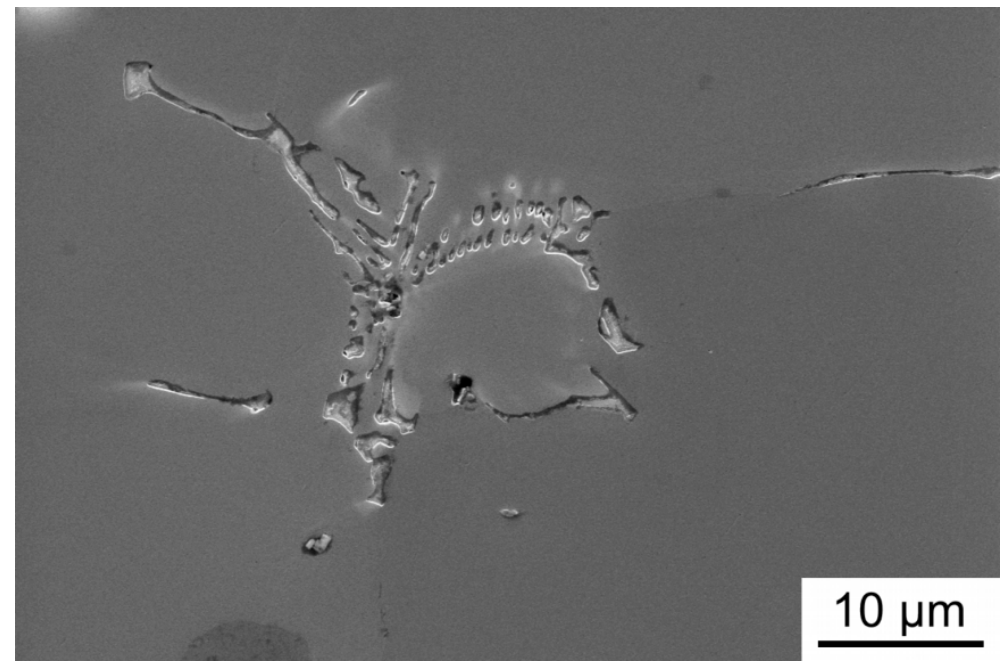

Figure 4. Intermetallic $\alpha$-AlFeMnSi phase in the cast non-homogenized rod.

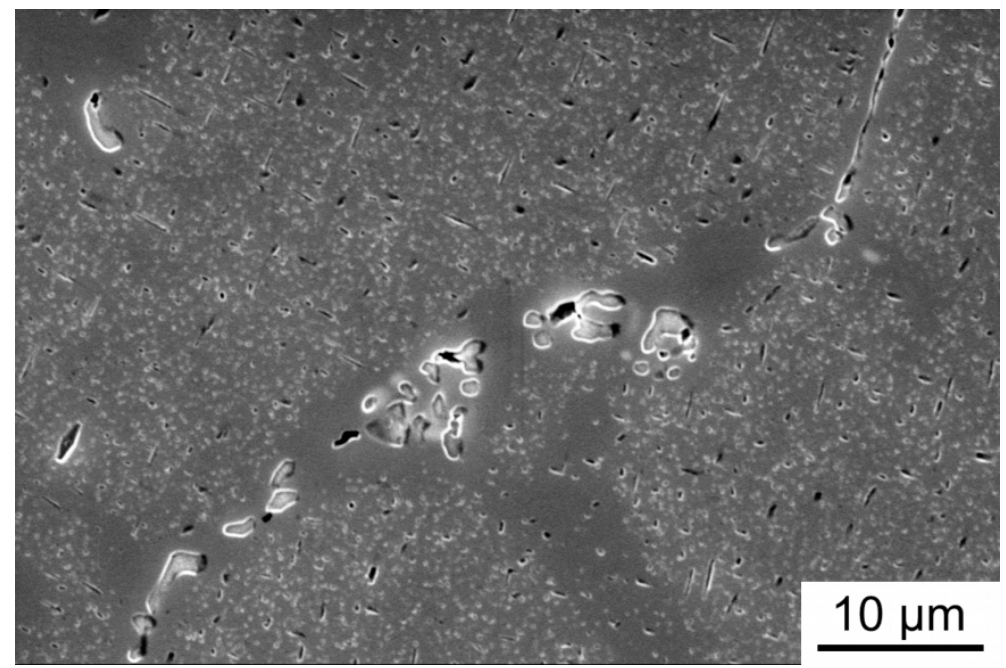

Figure 5. Intermetallic phase and precipitates in the cast homogenized rod. 


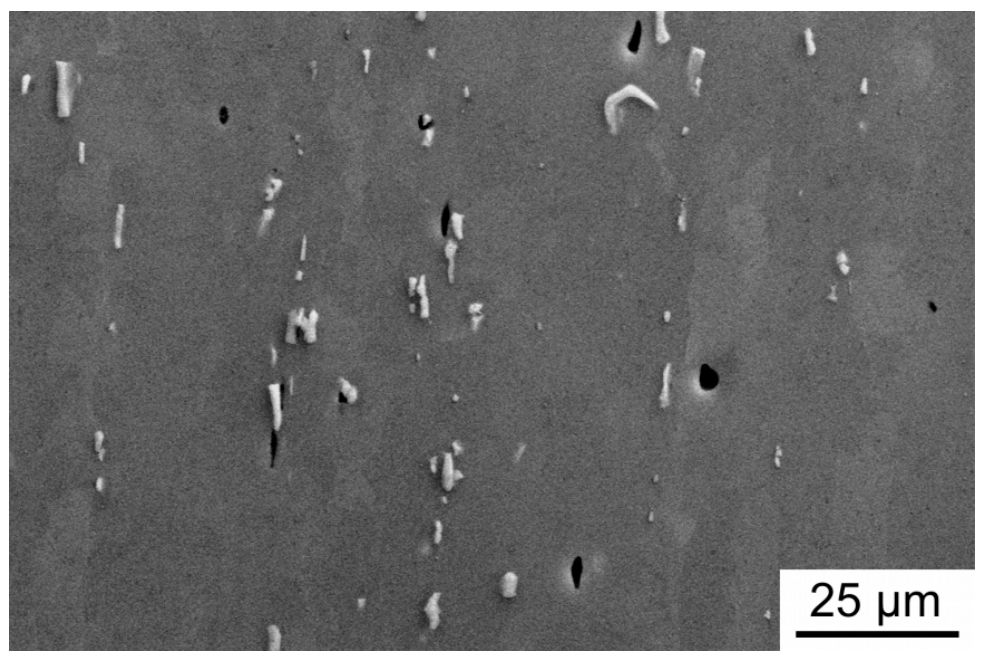

Figure 6. Disintegrated intermetallic phases in the extruded rod.

\section{Stress-Strain Curves}

Cylindrical samples with a diameter of $10 \mathrm{~mm}$ and a height of $15 \mathrm{~mm}$ were produced from the supplied material. On the Hydrawedge II module (component of the Gleeble 3800 hot deformation simulator (DSI, Poestenkill, NY, USA), the samples were subjected to uniaxial compression with the height reduction corresponding to a true strain of 0.7 . The samples were heated up to the forming temperature, i.e., $450{ }^{\circ} \mathrm{C}, 500^{\circ} \mathrm{C}$, and $550{ }^{\circ} \mathrm{C}$. The holding time of $500 \mathrm{~s}$ was followed by deformation at nominal strain rates of $0.5 \mathrm{~s}^{-1}, 1 \mathrm{~s}^{-1}, 5 \mathrm{~s}^{-1}$, and $10 \mathrm{~s}^{-1}$. The danger of falling off the usually welded thermocouples during the tests was eliminated by stuffing the K-type thermocouple wires into the holes drilled into the used samples. These holes were uniformly $1.0 \mathrm{~mm}$ in diameter and $1.5 \mathrm{~mm}$ deep. The deformed samples were cooled freely, without structure fixation, because only the initial structure of all three types of material was investigated with respect to the research objectives. The obtained curves of flow stress $\sigma[\mathrm{MPa}]$ depending on the true strain $e[-]$, temperature $T\left[{ }^{\circ} \mathrm{C}\right]$, and strain rate $\dot{e}$ $\left[\mathrm{s}^{-1}\right]$ were smoothed in the Origin software and digitized with a strain step of 0.02 . Examples of the resulting stress-strain curves are shown in comparative Figures 7 and 8 . The letter $C$ indicates the as-cast state, the letter $\mathrm{H}$ shows the state after homogenization, and the letter $\mathrm{E}$ indicates the state after hot extrusion. Stress values corresponding to the peak (i.e., maximum values in individual tests) $\sigma_{p}$ $[\mathrm{MPa}]$ and steady-state flow $\sigma_{s s}[\mathrm{MPa}]$ were determined for each curve. Since there are some stress changes even in the steady state, the $\sigma_{s s}$ values were determined by linear regression of the relevant data (parallel to the horizontal axis).

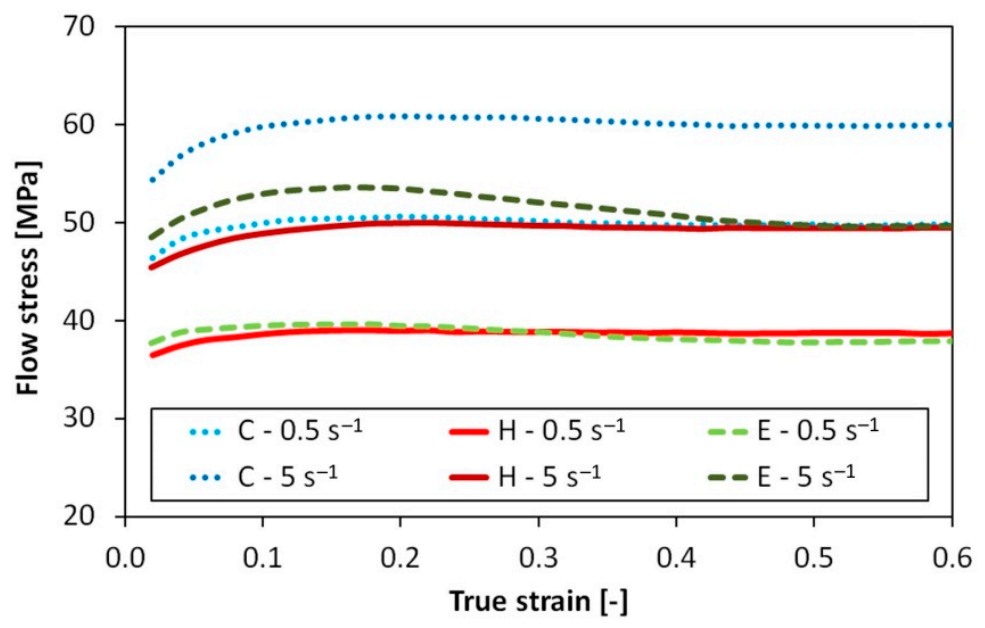

Figure 7. Stress-strain curves for a temperature of $450{ }^{\circ} \mathrm{C}$. 


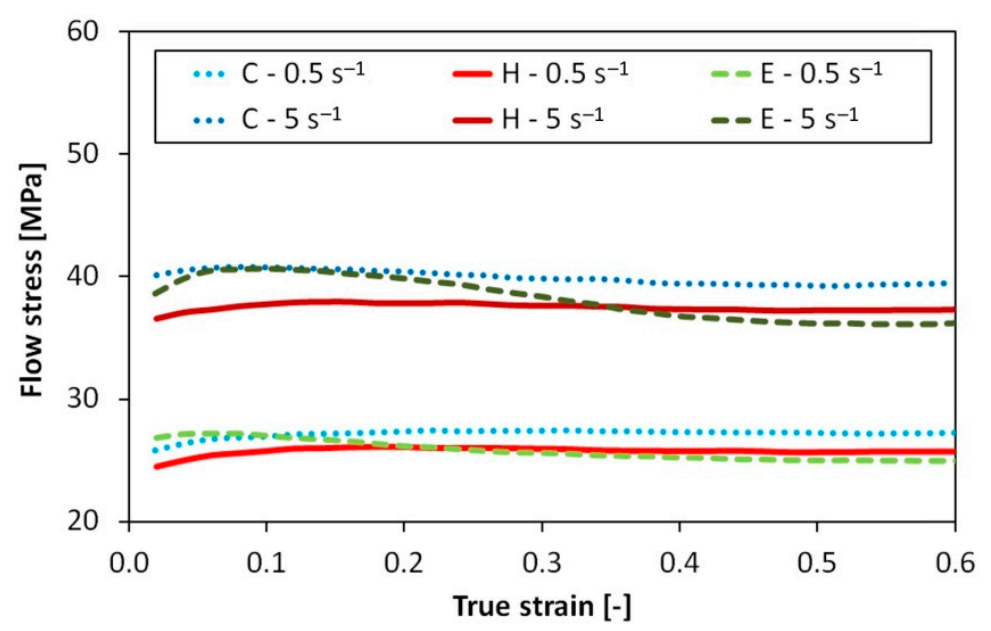

Figure 8. Stress-strain curves for a temperature of $550{ }^{\circ} \mathrm{C}$

\section{Hot Deformation Activation Energy}

The apparent activation energy value $Q\left[\mathrm{~J} \cdot \mathrm{mol}^{-1}\right]$ in hot forming is considered to be an important material constant, used primarily for calculating the Zener-Hollomon parameter $Z\left[\mathrm{~s}^{-1}\right.$ ] representing the temperature-compensated strain rate [19].

$$
Z=\dot{e} \cdot \exp \left(\frac{Q}{R \cdot T}\right)
$$

where $T[\mathrm{~K}]$ is temperature and $R=8.314 \mathrm{~J} \cdot \mathrm{mol}^{-1} \cdot \mathrm{K}^{-1}$ is the gas constant.

Knowledge of the $Q$ value for the given material enables, among others, to quickly predict the maximum flow stress value at the given temperature and strain rate [20]. The $Q$ value is ideally the material constant that depends only on the chemical composition and microstructure of the particular material. The hyperbolic law in the Arrhenius-type equation is conventionally used for its determination [21].

$$
\dot{e}=C \cdot \exp \left(\frac{-Q}{R \cdot T}\right) \cdot\left[\sinh \left(\alpha \cdot \sigma_{p}\right)\right]^{n}
$$

where $C\left[\mathrm{~s}^{-1}\right], n[-]$, and $\alpha\left[\mathrm{MPa}^{-1}\right]$ are other material constants. This relationship is often solved by a simple graphic method based on the repeatedly used linear regression [22]. A particularity of the hyperbolic function is used in this calculation, which simplifies Equation (2) for low stress values (i.e., $\left.\alpha \cdot \sigma_{p}<0.8\right)$ into the form of the power law.

$$
\dot{e}=C_{1} \cdot \exp \left(\frac{-Q}{R \cdot T}\right) \cdot \sigma_{p}{ }^{n}
$$

Vice versa, for high stress values (i.e., $\alpha \cdot \sigma_{p}>1.2$ ), the function simplifies the equation into the form of the exponential law.

$$
\dot{e}=C_{2} \cdot \exp \left(\frac{-Q}{R \cdot T}\right) \cdot \exp \left(\beta \cdot \sigma_{p}\right)
$$

where $C_{1}, C_{2}$, and $\beta$ are the material constants. The constant $\alpha$ in Equation (2) is given by the relationship $\alpha=\beta / n$. For a chosen high-temperature level (i.e., for low stress values), the constant $n$ is determined by the linear regression of the experimentally found values in the coordinates $\ln \dot{e}-\ln$ $\sigma_{p}$. For a chosen low-temperature level (i.e., for high stress values), the constant $\beta$ is obtained by the linear regression in the coordinates $\ln \dot{e}-\sigma_{p}$. After calculating the $\alpha$ quantity, the constants $Q$ and $C$ in Equation (2) can be obtained by the final linear regression of all data plotted in the coordinate system $\ln \dot{e}-n \cdot \ln \left(\sinh \left(\alpha \cdot \sigma_{p}\right)\right)-T^{-1}$. 
Such an estimate of constants $n$ and $\beta$ is a weak point of the described method since it can be strongly influenced by the selection of the corresponding temperature levels. This deficiency can be eliminated by the application of the specially developed software ENERGY 4.0 (VŠB-TU Ostrava, Czech Republic) [23], which uses the above-mentioned values of $n$ and $\beta$ only as the first estimate of parameters for the final refining nonlinear regression analysis of all data corresponding to Equation (2).

Calculation of the hot deformation activation energy from experimental $\sigma_{p}$-values on the basis of the hyperbolic-sine Equation (2) is the traditional method that was successfully applied for different types of materials, such as for various types of steel [24,25], intermetallic compounds [26], alloys based on copper [27], titanium [28], or magnesium [29].

Application of the peak stress $\sigma_{p}$ is, in this case, physically justified because it corresponds to similar structural states given by the course of dynamic recrystallization for different Z-parameter values. The same applies to the steady-state stress. By modifying Equation (2), general dependence of the flow stress $\sigma[\mathrm{MPa}]$ on parameter $Z$ can be expressed.

$$
\sigma=\frac{1}{\alpha} \cdot \operatorname{arcsinh} \sqrt[n]{\frac{Z}{C}}
$$

where flow stress should be $\sigma_{p}$ or $\sigma_{s s}$.

Table 2 presents the $Q$ values calculated by the methodology described above from the measured values of $\sigma_{p}$ or $\sigma_{s s}$ for all three initial structural states. An exceptionally low $Q_{p}$ value for the extruded state is due to somewhat greater scatter of $\sigma_{p}$ values measured at $450^{\circ} \mathrm{C}$.

Table 2. Hot deformation activation energy values calculated for various structural states.

\begin{tabular}{cccc}
\hline Energy & As-Cast & Homogenized & Extruded \\
\hline$Q_{p}\left[\mathrm{~kJ} \cdot \mathrm{mol}^{-1}\right]$ & 200.2 & 116.3 & 98.6 \\
$Q_{s s}\left[\mathrm{~kJ} \cdot \mathrm{mol}^{-1}\right]$ & 216.1 & 121.9 & 120.6 \\
\hline
\end{tabular}

\section{Discussion of Results}

The deformation properties of the as-cast structure are generally worse to those of the already deformed structure. Therefore, in die forging of aluminium alloys, hot-extruded cast rods are usually used as the starting stock. One of the innovative technological elements in forging aluminium alloys of the 6xxx series is the replacement of the extruded rods with cast rods. This procedure reduces the cost of the input material and the energy required for the production of extruded rods. Direct use of as-cast rods for forgings, however, involves one major technological operation, which is the homogenization of the as-cast structure. High-temperature homogenization of billets for forgings is usually used before the rods are extruded. This is a very energy-intensive operation, which significantly increases the cost of forgings. Therefore, there is an effort to eliminate this operation and to forge a non-homogenized material. The omission of homogenization annealing has an influence both on the state of structure and on its deformation behaviour as well as on the mechanical and fatigue properties of the final forgings. Since the as-cast structure is structurally and chemically heterogeneous and coarse-grained, it usually exhibits lower mechanical properties than the structure of extruded rods.

Hot deformation behaviour of 6082 aluminium alloy, supplied in the form of rods with a diameter of $55 \mathrm{~mm}$, was investigated. Continuous casting of such bars is a demanding process and often larger castings (e.g., with a diameter of $101 \mathrm{~mm}$ [30]) are used. Rods with a diameter of $55 \mathrm{~mm}$ can be used for forging products for the automotive industry, e.g., for the front axle components. The use of cast and non-homogenized material would result in significant savings over the conventional extruded bars. This would save on the cost of homogenizing the large diameter rods and the bars' extrusion. Yet, it is necessary to decide whether or not homogenizing annealing of the cast rods is indispensable.

Figures 7 and 8 demonstrate that the initial extruded state results in more pronounced softening due to dynamic recrystallization of the finer grains. Stress-strain curves corresponding to both as-cast 
states are flatter, with less of a difference between $\sigma_{p}$ and $\sigma_{s s}$ values. This is a sign of a delay in dynamic recrystallization. Especially at low temperatures, the as-cast non-homogenized material exhibits significantly higher flow stress likely due to a specific characteristic of intermetallic phases in the interdendritic spaces.

Table 2 shows that, in all cases, relationship $Q_{s s}>Q_{p}$ came out with an average difference of $12 \%$. This has confirmed that the $Q$ value is not strictly a material constant but depends on the amount of strain. In most cases, however, for metal alloys with significant peak stress, the value of the activation energy more or less decreases not quite monotonically, with increasing strain. The results were obtained for 17-4 PH stainless steel [31], Q420qE microalloyed steel [32], T24 ferritic steel [33], and Ti-6Al-4V titanium alloy [34]. The prevailing opposite trend was observed, e.g., in AZ81 magnesium alloy [35]. The discrepancy between $Q_{p}$ and $Q_{s s}$ values should be due to a different dislocation density and grain character at the respective strains.

Corresponding $Q$ values are very close in case of the homogenized and extruded state, but about $80 \%$ higher for the as-cast state. This indicates a very pronounced effect of homogenization on the deformation behaviour of the as-cast structure. Homogenization annealing changes the size, shape, and chemical composition of the intermetallic phases at grain boundaries (see Chapter 2 for more details). As a result of homogenization, large $\alpha$-AlFeMnSi phases (see Figure 4) break down into smaller and rounded particles into which the elements dissolved in the matrix diffuse. At the same time, dendritic segregation in the as-cast grains is removed. Phases are formed which, by their size and non-coherence with the surrounding matrix, can result in the relatively lower flow stress and hot deformation activation energy in comparison with the structure prior to homogenization. The $Q_{s s}$ values of the two homogenized materials indicate that, at large strains, there are no significant differences in the structure state of the initial as-cast and extruded material. The $Q$ values calculated by other authors for various aluminium alloys including a 6082 type are shown in Table 3 for comparison.

Table 3. Values of hot deformation activation energy calculated for various aluminium alloys.

\begin{tabular}{ccc}
\hline Alloy & $Q$ [kJ· $\mathbf{m o l}^{\mathbf{- 1}}$ ] & Reference \\
\hline 2024 (As-cast) & 345 & {$[36]$} \\
2026 (Homogenized) & 341 & {$[37]$} \\
6082 (Homogenized) & 191 & {$[30]$} \\
6082 (Extruded) & 269 & {$[38]$} \\
6082 (Artificially aged) & 228 & {$[39]$} \\
6082 (N/A) & 175 & {$[40]$} \\
6082 (Homogenized) & 182 & {$[41]$} \\
6082 (Naturally aged) & 245 & {$[42]$} \\
7050 (As-rolled) & $237-241$ & {$[43]$} \\
Al-Mg-Si-Cu (Homogenized) & 236 & {$[44]$} \\
\hline
\end{tabular}

It should be emphasized that the comparison of the calculated $Q$ values with literary sources can be significantly influenced by various experimental conditions (specific chemical composition of the material, initial structure state, type of deformation test, range of temperature, and strain rate) and, to a certain extent, by the methodology used to process the experimental results [23]. In Table 3 , the activation energy values for the 6082 alloy range from 191 to $269 \mathrm{~kJ} \cdot \mathrm{mol}^{-1}$. Their average value of $215 \mathrm{~kJ} \cdot \mathrm{mol}^{-1}$ corresponds very accurately to the activation energy $Q_{s s}=216 \mathrm{~kJ} \cdot \mathrm{mol}^{-1}$ for the as-cast state in Table 2. However, it is significantly lower than all $Q$ values calculated for the materials subjected to homogenization annealing (see Table 2). The difference with the result of Spigarelli, Evangelista, and McQueen [38] (i.e., $Q=269 \mathrm{~kJ} \cdot \mathrm{mol}^{-1}$ ) is particularly significant. In this case, the initial structures were somewhat different for various testing temperatures $\left(200-500^{\circ} \mathrm{C}\right)$ when each sample was treated at $530{ }^{\circ} \mathrm{C}$ for $2 \mathrm{~h}$, and then aged for $24 \mathrm{~h}$ at the temperature selected for the torsion test. This treatment was intended to produce a stable structure, in terms of particle population, which avoids any significant process of precipitation and/or coarsening of the precipitates during deformation. The resulting 
stress-strain curves differ significantly from those in Figures 7 and 8 when exhibiting marked peaks but no signs of subsequent transition to a steady-state. The results conclude that the high-temperature deformation of the 6082 alloys with stable dispersion of precipitates is recovery-controlled.

$\mathrm{Li}$ et al. [45] studied the hot deformation behaviour of the 6082 alloy after semi-continuous casting and homogenization at $545{ }^{\circ} \mathrm{C}$ for $24 \mathrm{~h}$. Using Equations (2)-(4), they calculated the hot deformation activation energy repeatedly under different strains ranging from 0.10 to 0.65 . The results are demonstrated in Figure 9. Dependence $Q(e)$ is rather complicated, and is originally described by a 7th order polynomial fit. The activation energy value varies significantly within a narrow range of about $172-178 \mathrm{~kJ} \cdot \mathrm{mol}^{-1}$ and is, therefore, higher than the $Q$ values for the homogenized state in Table 2 (i.e., 116 or $122 \mathrm{~kJ} \cdot \mathrm{mol}^{-1}$ ), but below these values for the as-cast state (i.e., 200 or $216 \mathrm{~kJ} \cdot \mathrm{mol}^{-1}$ ). This may also be due to higher silicon content of $1.30 \%$ versus $0.93 \%$ (see Table 1 ). An unexplained course of dependence $Q(e)$ in Figure 9 demonstrates the growth of the $Q$ value at the highest strains applied, which is consistent with the finding that relationship $Q_{s s}>Q_{p}$ aligns with the material under investigation. However, it is necessary to draw attention to the principal differences in the calculation of $Q$ values from the stress values corresponding to particular deformations, respectively from the $\sigma_{p}$ or $\sigma_{s s}$ values. The specific stress values corresponding to the peak or steady state on the stress-strain curve are the result of deformation strengthening and dynamic softening processes, and, therefore, have a similar physical significance for the different values of the Zener-Hollomon parameter. In contrast, stresses corresponding to particular strain values at different $Z$ values may correspond to qualitatively different structural states of the deformed material.

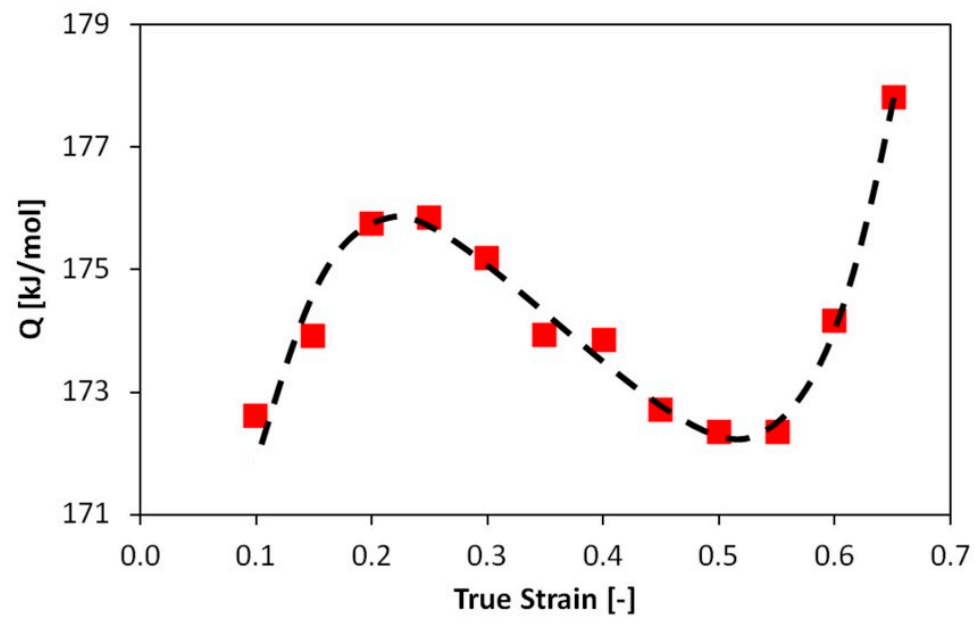

Figure 9. Effect of the true strain on the $Q$ value of the homogenized 6082 alloy, according to Reference [45].

Figure 10 as well as the data in Tables 2 and 4 clearly show the different deformation behaviours of the as-cast 6082 alloy and the material after homogenization annealing, especially at lower deformation temperatures. The individual lines in Figure 10 were obtained by regression analysis and correspond to a simple exponential function.

Based on the knowledge of all material constants in Equation (5), the dependence of the stress $\sigma_{p}$ or $\sigma_{s s}$ on the $Z$ parameter could be plotted in Figures 11 and 12. These black lines can be compared to the measured values (colour-coded points), which are also related to the temperature-compensated strain rate. The different $Z$ values for the same combination of temperature and strain rate are the result of different activation energy values (see Table 2) being applied in Equation (1). The accuracy of the mathematical description of the $\sigma_{p}$ and $\sigma_{s s}$ values with a total of six equations is very good in the whole range of applied deformation conditions, with an average standard deviation of only $1 \mathrm{MPa}$.

Significant differences of comparable values of $\sigma_{p}$ and $\sigma_{s S}$ in the case of the initial as-cast state and of both states after homogenization annealing illustrates how crucial the effect of homogenization on 
the strengthening and softening processes is in the tested alloy. Homogenization leads to a relative reduction of the flow stress during forming at elevated temperatures. The influence of the previous plastic deformation (cast versus extruded material) is much smaller, and it is even negligible in case of $\sigma_{s s}$ values related to large strains.

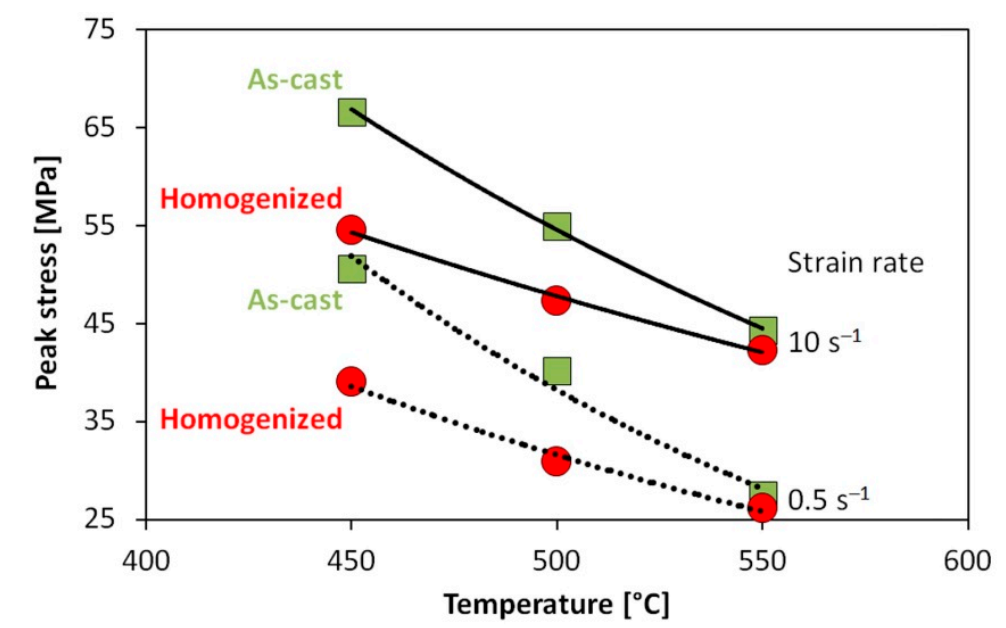

Figure 10. Influence of homogenization on the $\sigma_{p}$ values measured at different temperatures and selected strain rate values.

Table 4. Constants in Equation (5) calculated for the individual initial structural states.

\begin{tabular}{ccccc}
\hline Stress Type & Constant & As-Cast & Homogenized & Extruded \\
\hline \multirow{3}{*}{ Peak } & $n[-]$ & 1.03 & 3.58 & 3.07 \\
& $\alpha\left[\mathrm{MPa}^{-1}\right]$ & 0.18 & 0.05 & 0.05 \\
& $C\left[\mathrm{~s}^{-1}\right]$ & $2.7 \times 10^{10}$ & $1.7 \times 10^{6}$ & $1.1 \times 10^{5}$ \\
\hline \multirow{3}{*}{ Steady State } & $n[-]$ & 1.19 & 3.24 & 2.88 \\
& $\alpha\left[\mathrm{MPa}^{-1}\right]$ & 0.17 & 0.06 & 0.07 \\
& $C\left[\mathrm{~s}^{-1}\right]$ & $2.2 \times 10^{11}$ & $2.2 \times 10^{6}$ & $1.7 \times 10^{6}$ \\
\hline
\end{tabular}

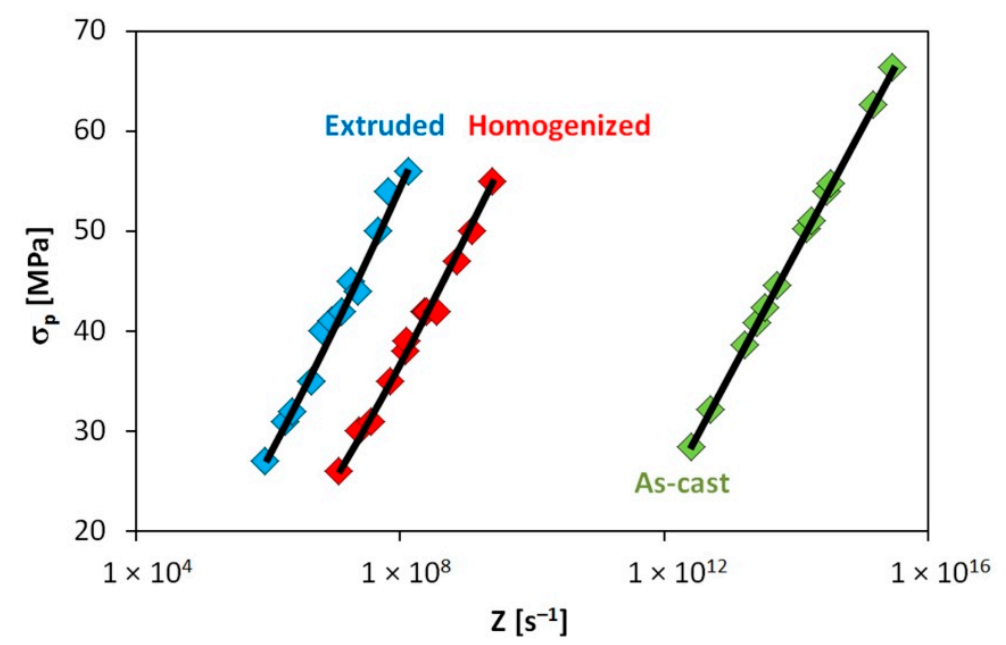

Figure 11. Dependence of measured and calculated values of $\sigma_{p}$ on the Zener-Hollomon parameter and the initial structural state. 


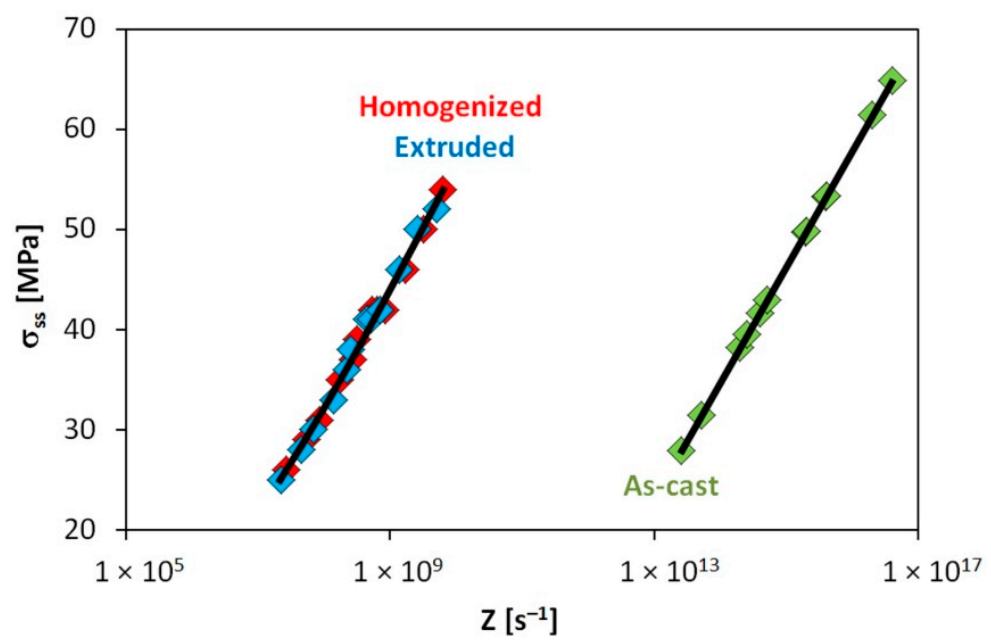

Figure 12. Dependence of measured and calculated values of $\sigma_{S S}$ on the Zener-Hollomon parameter and the initial structural state.

It is worth noting that, in the real extrusion and die forging processes of the 6082 alloy, the strain rate is so high that a strain corresponding to the peak stress cannot be achieved. Therefore, dynamic recrystallization cannot be initiated. The resulting structure is mostly worked on and recovered. Recrystallization occurs only in places of extreme shear deformation (i.e., in the surface areas due to a contact of the material with the forming tool), and only after forging of the extruded rods (see Figure 13).

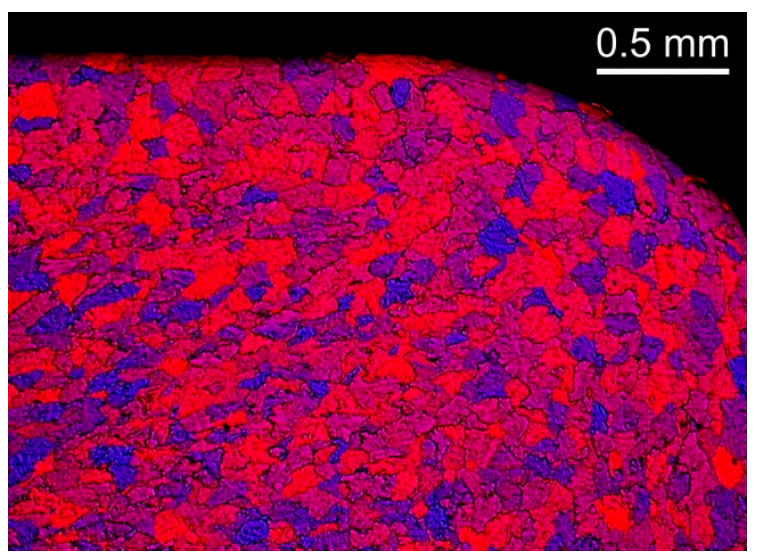

(a)

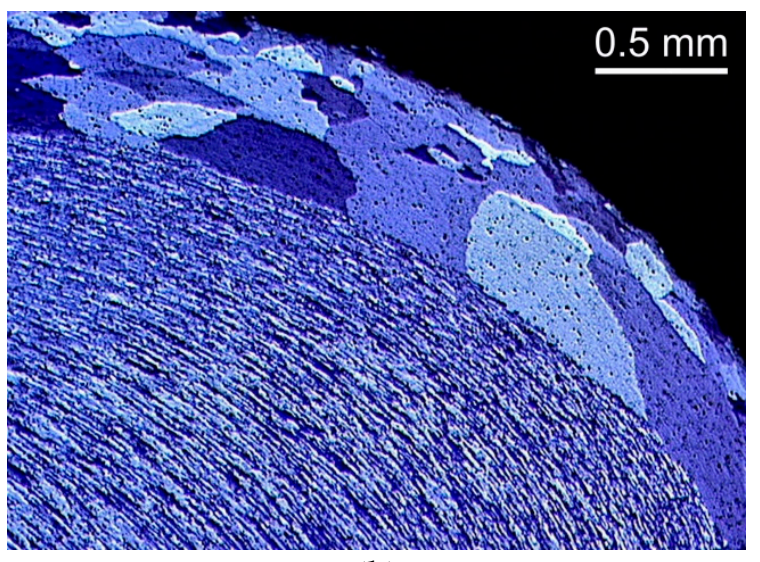

(b)

Figure 13. Effect of the initial structure state on the forged microstructure of the 6082 alloy [46]. (a) Forging from the cast non-homogenized rod-surface area. (b) Forging from the extruded rod and the coarse-grained recrystallized surface layer.

Equation (5) is mainly used for a quick prediction of maximum flow stress at specific values of strain rate and temperature. However, the knowledge of hot forming activation energy can be used in more complicated stress-strain curve calculations that reflect deformation strengthening as well as dynamic softening. Using the value of $Q_{p}=98.6 \mathrm{~kJ} \cdot \mathrm{mol}^{-1}$, the strain $e_{p}[-]$ corresponding to the peak stress in dependence on the $Z$ parameter has been described for the extruded state. The commonly used type of power function $[47,48]$ was applied for regression analysis of the peak strain data.

$$
e_{p}=0.0053 \cdot Z^{0.19}
$$


Based on the prediction of strain $e_{p}$, the constants in Equation (7) were determined by multiple non-linear regression in Unistat software, which allows calculation of flow stress $\sigma$ [MPa] of a tested material depending on temperature $T[\mathrm{~K}]$, strain rate $\dot{e}\left[\mathrm{~s}^{-1}\right]$, and true strain $e[-]$ (up to $e=0.6$ ).

$$
\sigma=515 \cdot e^{0.031} \cdot \exp \left(-0.031 \cdot \frac{e}{e_{p}}\right) \cdot e^{\left(0.51-\frac{293}{T}\right)} \cdot \exp (-0.0033 \cdot T)
$$

This type of constitutive model [49-51] was originally designed only for smaller strains than achieved by the steady state but is also applicable to relatively flat shape curves. Its advantage is simplicity and physical basis represented by strain $e_{p}(Z)$, which corresponds to the initiation of dynamic recrystallization.

Figure 14 compares the measured stress values with the values calculated according to Equation (7) for the individual flow curves (characterized by temperature and strain rate). The horizontal axis corresponds to the extent of true strain $0.02 \leq e \leq 0.60$ for individual curves. The deviation of the predicted stress values ranges from -2.2 to $2.9 \mathrm{MPa}$, the standard deviation is $1.0 \mathrm{MPa}$, and the coefficient of determination is $R^{2}=0.9861$ for the developed model. The accuracy of Equation (7) is, therefore, satisfactory over a given range of deformation conditions. It is comparable with the much more complex phenomenological Arrhenius-type model developed by Li et al. [45] for the homogenized 6082 alloy (with $R^{2}=0.9890$ ).

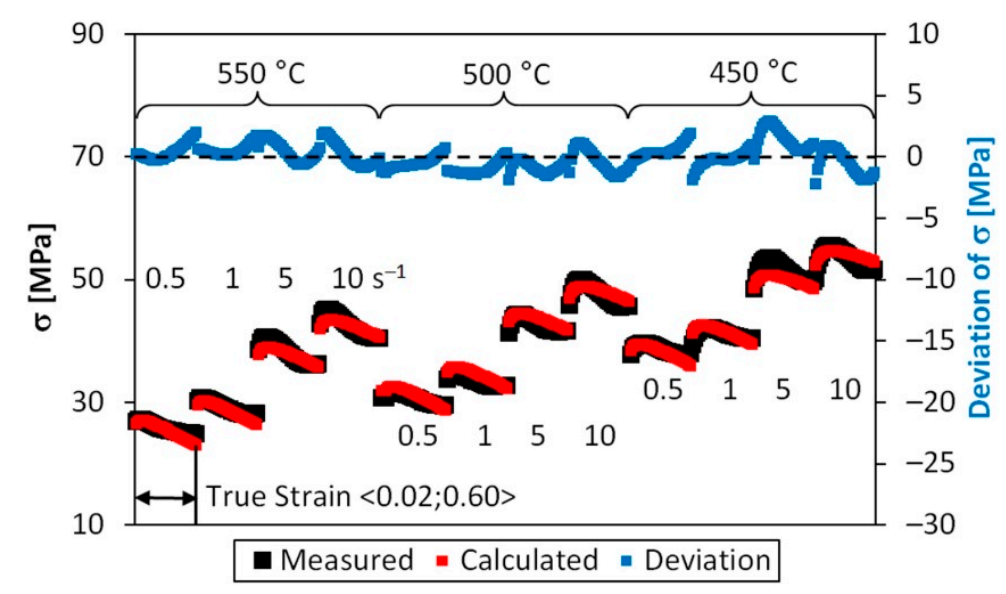

Figure 14. Graphical evaluation of the accuracy of the flow stress prediction according to Equation (7).

\section{Conclusions}

Stress-strain curves of EN AW 6082 aluminium alloy at a temperature of $450-550{ }^{\circ} \mathrm{C}$ and a strain rate of $0.5-10 \mathrm{~s}^{-1}$ were obtained from the series of uniaxial compression tests. Initial structure state corresponded to three processing types: as-cast structure non-homogenized or homogenized, and the structure after homogenization and hot extrusion. Especially at low temperatures, the as-cast non-homogenized material exhibits significantly higher flow stress.

The values of apparent activation of energy in hot forming were calculated based on peak stress (energy $Q_{p}$ ) and steady-state stress (energy $Q_{s s}$ ). The $Q$ values were influenced by the amount of strain. In all cases, relationship $Q_{s s}>Q_{p}$ came out with an average difference of $12 \%$. There was a significant effect of homogenization on the deformation behaviour of the as-cast structure via changes of intermetallic phases at the boundaries of the original grains. Corresponding $Q$ values are similar to the homogenized and extruded state $\left(99-122 \mathrm{~kJ} \cdot \mathrm{mol}^{-1}\right)$, but about $80 \%$ higher for the as-cast state $\left(200-216 \mathrm{~kJ} \cdot \mathrm{mol}^{-1}\right)$.

The hot stress-strain curves of the extruded material were described with good accuracy by the constitutive model reflecting the influence of dynamic softening. The calculated activation energy was used for the necessary prediction of peak strain depending on the Zener-Hollomon parameter. 
The simple model will be used for computer simulation of the optimization simulation of real die forging processes for accurate prediction of the forming forces.

Author Contributions: Conceptualization, I.S.; methodology, I.S.; software, P.O.; investigation, R.K., P.K., S.R. and V.O.; resources, V.O.; data curation, P.K. and I.S.; writing - original draft, I.S. and V.O.; writing - review and editing, I.S., S.R., P.O. All authors revised and approved the final version of the manuscript.

Funding: This paper was created in the project No. CZ.1.05/2.1.00/19.0387 "Development of research and development basis of RMSTC" within the frame of the operation programme Research and Development for Innovations financed by the Structural Funds and from the state budget of the Czech Republic, and in the internal grant project SP2019/86 supported at the VSB-TU Ostrava by the Ministry of Education of the Czech Republic.

Conflicts of Interest: The authors declare no conflict of interest.

\section{References}

1. ASM International. ASM Specialty Handbook: Aluminum and Aluminum Alloys; ASM International, Materials Park: Russell, OH, USA, 1993; p. 784.

2. Hirsch, J. Virtual Fabrication of Aluminium Products; Wiley-VCH Verlag GmbH \& Co. KGaA: Weinheim, Germany, 2006; p. 33.

3. Mrówka-Nowotnik, G.; Sieniawski, J.; Wierzbińska, M. Intermetallic phase particles in 6082 aluminium alloy. Arch. Mater. Sci. Eng. 2007, 28, 69-76.

4. Lodgaard, L.; Ryum, N. Distribution of Mn- and Cr-containing dispersoids in Al-Mg-Si-alloys. Mater. Sci. Forum 2000, 331, 945-950. [CrossRef]

5. Reiso, O. Extrusion of AlMgSi Alloys. In Proceedings of the 9th International Conference on Aluminum Alloys, Brisbane, Australia, 2-5 August 2014; pp. 32-46.

6. Tomovic-Petrovic, S.; Jensrud, O. Extrusion of silicon-rich AlMgSi alloys. J. Mater. Process. Technol. 2012, 212, 1437-1442. [CrossRef]

7. Kuijpers, N.C.W.; Kool, W.H.; van der Zwaag, S. DSC study on Mg-Si phases in As cast AA6xxx. Mater. Sci. Forum 2002, 396, 675-680. [CrossRef]

8. Mrówka-Nowotnik, G.; Sieniawski, J. Influence of heat treatment on the microstructure and mechanical properties of 6005 and 6082 aluminium alloys. J. Mater. Process. Technol. 2005, 162, 367-372. [CrossRef]

9. Hu, R.; Ogura, T.; Tezuka, H.; Sato, T.; Liu, Q. Dispersoid formation and recrystallization behavior in an Al-Mg-Si-Mn alloy. J. Mater. Sci. Technol. 2010, 26, 237-243. [CrossRef]

10. Birol, Y.; Ilgaz, O. Effect of cast and extruded stock on grain structure of EN AW 6082 alloy forgings. Mater. Sci. Technol. 2014, 30, 860-866. [CrossRef]

11. Birol, Y.; Gokcil, E.; Akdi, S. Potential of horizontal direct chill cast EN AW 6082 rods as forging stock in the manufacture of light weight suspension components. Metall. Res. Technol. 2017, 114, 209. [CrossRef]

12. Birol, Y.; Gokcil, E.; Akdi, S. Potential of twin-belt-cast EN AW 6082 blanks for the manufacture of wishbone suspension forgings. Int. J. Adv. Manuf. Technol. 2017, 92, 3693-3701. [CrossRef]

13. Li, J.H.; Wimmer, A.; Dehm, G.; Schumacher, P. Intermetallic phase selection during homogenization for AA6082 alloy. Philos. Mag. 2014, 94, 830-846. [CrossRef]

14. Rometsch, P.A.; Wang, S.C.; Harriss, A.; Gregson, P.J.; Starink, M.J. The effect of homogenizing on the quench sensitivity of 6082. Mat. Sci. Forum 2002, 396, 655-660. [CrossRef]

15. Woźnicki, A.; Leśniak, D.; Włoch, G.; Leszczyńska-Madej, B.; Wojtyna, A. The effect of homogenization conditions on the structure and properties of 6082 alloy billets. Arch. Metall. Mater. 2015, 60, 1763-1771. [CrossRef]

16. Chang, Y.L.; Hung, F.Y.; Lui, T.S. Enhancement of mechanical properties of hot-forged 6082 suspension parts via rapid IR heat treatment. Metals 2018, 8, 501. [CrossRef]

17. Zajac, S.; Bengtsson, B.; Jönsson, C. Influence of cooling after homogenization and reheating to extrusion on extrudability and final properties of AA 6063 and AA 6082 alloys. Mater. Sci. Forum 2002, 396, 399-404. [CrossRef]

18. Warmuzek, M.; Sieniawski, J.; Gazda, A.; Mrówka, G. Processes of the formation of the Fe (Mn)-bearing intermetallic phases in the Al-Fe-(Mn)-Si alloys. Adv. Mater. Sci. 2003, 4, 81-91.

19. Zener, C.; Hollomon, J.H. Effect of strain rate upon plastic flow of steel. J. Appl. Phys. 1944, 15, 22-32. [CrossRef] 
20. Schindler, I.; Kawulok, R.; Kulveitová, H.; Kratochvíl, P.; Šíma, V.; Knapiński, M. Activation energy in hot forming of selected Fe-40at.\%Al type intermetallic compounds. Acta Phys. Pol. A 2012, 122, 610-613. [CrossRef]

21. Sellars, C.M.; Tegart, W.M. Hot Workability. Int. Metall. Rev. 1972, 17, 1-24. [CrossRef]

22. McQueen, H.J.; Yue, S.; Ryan, N.D.; Fry, E. Hot working characteristics of steels in austenitic state. J. Mater. Process. Technol. 1995, 53, 293-310. [CrossRef]

23. Schindler, I.; Kawulok, P.; Kawulok, R.; Hadasik, E.; Kuc, D. Influence of calculation method on value of activation energy in hot forming. High. Temp. Mater. Processes 2013, 32, 149-155. [CrossRef]

24. Kawulok, P.; Schindler, I.; Kawulok, R.; Opěla, P.; Sedláček, R. Influence of heating parameters on flow stress curves of low-alloy Mn-Ti-B steel. Arch. Metall. Mater. 2018, 63, 1785-1792. [CrossRef]

25. Zheng, S.; Yuan, X.; Gong, X.; Le, T.; Ravindra, A.V. Hot deformation behavior and microstructural evolution of an Fe-Cr-W-Mo-V-C steel. Metall. Mater. Trans. A 2019, 50, 2342-2355. [CrossRef]

26. Singh, V.; Mondal, C.; Kumar, A.; Bhattacharjee, P.P.; Ghosal, P. High temperature compressive flow behavior and associated microstructural development in a $\beta$-stabilized high $\mathrm{Nb}$-containing $\gamma$-TiAl based alloy. $J$. Alloys Compd. 2019, 788, 573-585. [CrossRef]

27. Schindler, I.; Sauer, M.; Kawulok, P.; Rodak, K.; Hadasik, E.; Jabłońska, M.B.; Rusz, S.; Ševčák, V. Study of hot deformation behavior of $\mathrm{CuFe}_{2}$ alloy. Arch. Metall. Mater. 2019, 64, 701-706. [CrossRef]

28. Zhao, Q.; Yang, F.; Torrens, R.; Bolzoni, L. Comparison of hot deformation behaviour and microstructural evolution for Ti-5Al-5V-5Mo-3Cr alloys prepared by powder metallurgy and ingot metallurgy approaches. Mater. Des. 2019, 169, 107682. [CrossRef]

29. Schindler, I.; Kawulok, P.; Hadasik, E.; Kuc, D. Activation energy in hot forming and recrystallization models for magnesium alloy AZ31. J. Mater. Eng. Perform. 2013, 22, 890-897. [CrossRef]

30. Qian, X.; Parson, N.; Grant Chen, X. Effects of Mn addition and related Mn-containing dispersoids on the hot deformation behavior of 6082 aluminum alloys. Mater. Sci. Eng. A 2019, 764, 138253. [CrossRef]

31. Mirzadeh, H.; Najafizadeh, A. Flow stress prediction at hot working conditions. Mater. Sci. Eng. A 2010, 527, 1160-1164. [CrossRef]

32. Yu, B.J.; Guan, X.J.; Wang, L.J.; Zhao, J.; Liu, Q.Q.; Cao, Y. Hot deformation behavior and constitutive relationship of Q420qE steel. J. Cent. South. Univ. Technol. 2011, 18, 36-41. [CrossRef]

33. Li, H.Y.; Wei, D.D.; Hu, J.D.; Li, Y.H.; Chen, S.L. Constitutive modeling for hot deformation behavior of T24 ferritic steel. Comput. Mater. Sci. 2012, 53, 425-430. [CrossRef]

34. Shafaat, M.A.; Omidvar, H.; Fallah, B. Prediction of hot compression flow curves of Ti-6Al-4V alloy in $\alpha+\beta$ phase region. Mater. Des. 2011, 32, 4689-4695. [CrossRef]

35. Changizian, P.; Zarei-Hanzaki, A.; Roostaei, A.A. The high temperature flow behavior modeling of AZ81 magnesium alloy considering strain effects. Mater. Des. 2012, 39, 384-389. [CrossRef]

36. Zhang, X.; Ma, F.; Zhang, W.; Li, X. Kinetics of dynamic recrystallization in AA2024 aluminum alloy. Mod. Appl. Sci. 2014, 8, 47-52. [CrossRef]

37. Huang, X.; Zhang, H.; Han, Y.; Wu, W.X.; Chen, J.H. Hot deformation behavior of 2026 aluminum alloy during compression at elevated temperature. Mater. Sci. Eng. A 2010, 527, 485-490. [CrossRef]

38. Spigarelli, S.; Evangelista, E.; McQueen, H.J. Study of hot workability of a heat treated AA6082 aluminum alloy. Scripta Mater. 2003, 49, 179-183. [CrossRef]

39. Soliman, M.S.; El-Danaf, E.; Almajid, A.A. Effect of heat treatment conditions on the high temperature deformation of 6082-Al alloy. Adv. Mater. Res. 2010, 83, 407-414. [CrossRef]

40. Ren, W.; Xu, C.; Chen, X. Hot deformation behavior and dynamic recrystallization model of 6082 aluminum alloy in high temperature. IOP Conf. Ser. Mater. Sci. Eng. 2018, 381, 012175. [CrossRef]

41. Wang, P.; Jiang, H.; Zhang, R.; Huang, S. Study of hot deformation behavior of 6082 aluminum alloy. Mater. Sci. Forum 2016, 877, 340-346. [CrossRef]

42. El-Danaf, E.A.; AlMajid, A.A.; Soliman, M.S. Hot deformation of AA6082-T4 aluminum alloy. J. Mater. Sci. 2008, 43, 6324-6330. [CrossRef]

43. Sang, D.L.; Fu, R.D.; Li, Y.J. The hot deformation activation energy of 7050 aluminum alloy under three different deformation modes. Metals 2016, 6, 49. [CrossRef]

44. Zhang, H.; Li, L.X.; Yuan, D.; Peng, D.S. Hot deformation behavior of the new Al-Mg-Si-Cu aluminum alloy during compression at elevated temperatures. Mater. Charact. 2007, 58, 168-173. [CrossRef] 
45. Li, K.; Pan, Q.; Li, R.; Liu, S.; Huang, Z.; He, X. Constitutive modeling of the hot deformation behavior in 6082 aluminum alloy. J. Mater. Eng. Perform. 2019, 28, 981-994. [CrossRef]

46. Luštinec, J.; Očenášek, V.; Jelínek, M. Structure of Al-Mg-Si cast and extruded rods for die forgings. Manuf. Technol. J. Sci. Res. Prod. 2016, 16, 1009-1013.

47. Mirzadeh, H.; Cabrera, J.M.; Prado, J.M.; Najafizadeh, A. Hot deformation behavior of a medium carbon microalloyed steel. Mater. Sci. Eng. A 2011, 528, 3876-3882. [CrossRef]

48. Li, Ch.; Liu, Y.; Tan, Y.; Zhao, F. Hot deformation behavior and constitutive modeling of H13-mod steel. Metals 2018, 8, 846. [CrossRef]

49. Schindler, I.; Kliber, J.; Bořuta, J. Prediction of Deformation Resistances at High-reduction Forming. In Proceedings of the 3rd Symposium Metal 94, Ostrava, Czech Republic, 10-12 May 1994; pp. 132-142.

50. Schindler, I.; Bořuta, J. Utilization Potentialities of the Torsion Plastometer; Silesian Technical University: Katowice, Poland, 1998; 106 p.

51. Legerski, M.; Plura, J.; Schindler, I.; Rusz, S.; Kawulok, P.; Kulveitova, H.; Hadasik, E.; Kuc, D.; Niewielski, G. Complex flow stress model for a magnesium alloy AZ31 at hot forming. High. Temp. Mater. Processes 2011, 30, 63-69. [CrossRef]

(C) 2019 by the authors. Licensee MDPI, Basel, Switzerland. This article is an open access article distributed under the terms and conditions of the Creative Commons Attribution (CC BY) license (http://creativecommons.org/licenses/by/4.0/). 